\title{
LOS PARADIGMAS FEMENINOS PLASMADOS EN EL ARTE Y LA \\ PERCEPCIÓN DE LA MUJER DE PRINCIPIOS DEL SIGLO XXI EN MÉXICO Y LATINOAMÉRICA
}

Feminine paradigms embodied in art and perception of women at the beginning of the 21st century in Mexico and Latin America

Gabriela Arhelí García Guerra Coral Revueltas Valle

ISSN (imp): 1390-4825

ISSN (e): 2477-9199

Fecha de recepción: 03/27/19

Fecha de aceptación: 05/03/19 


\section{Resumen:}

La imagen de la mujer representada en el arte se ha transformado de acuerdo al contexto de su época, el cual a su vez estuvo sometido a creencias y propósitos. A dos décadas del siglo XXI es posible identificar los orígenes de los paradigmas en la imagen femenina, así como hacer una crítica hacia estos pensamientos, hoy en día obsoletos. De tal manera, el presente texto tiene como propósito señalar algunas de las concepciones femeninas, principalmente en México y Latinoamérica. Primero, se señala, por medio de diferentes autores, como las obras artísticas contienen latentemente elementos de dominación sobre el cuerpo de la mujer, pero también sobre otros grupos vulnerables. Por último, se encuentra, a modo de conclusión, distintas reflexiones sobre el sentido del arte y el poder que tiene sobre los espectadores.

\section{Palabras clave:}

imagen femenina, colonización, arte, representación de paradigmas

\section{Abstract:}

Women image represented in art has been transformed according to their context, which followed beliefs and purposes. Two decades ahead, 21st century, it is possible to recognize paradigms origins for feminine image, as well as to make a criticism towards these obsolete thoughts nowadays. In this way, this article hopes to show some of the feminine conceptions, mainly in Mexico and Latin America. It is pointed out by different authors and artistic works, imply that elements of domination over woman's body can be seen in this context, but also are applied over other vulnerable groups. Finally, different thoughts on the meaning of art and the power it has on viewers.

\section{Key Words:}

feminine image, colonization, art, representation of paradigms

\section{Biografía de las autoras:}

Gabriela Arhelí García Guerra, (Chihuahua, México, 1990). Tiene una licenciatura en Artes Visuales y una maestría en Estudios y Procesos Creativos en Arte y Diseño, en la Universidad Autónoma de Ciudad Juárez. Actualmente cursa el segundo semestre en el Doctorado en Educación, Artes y Humanidades en la Universidad Autónoma de Chihuahua. Su registro en Orcid es: orcid.org/0000-0002-3339-1840.

Coral Revueltas Valle. Doctora en Imagen, Arte, Cultura y Sociedad por la UAEM; realizó la Maestría en Artes Visuales en la Academia de San Carlos FAD UNAM y la Licenciatura en Grabado en La Esmeralda, de la Escuela Nacional de Pintura, Escultura y Grabado del Instituto Nacional de Bellas Artes. Ha sido becaria del Sistema Nacional de Creadores de Arte del FONCA en dos ediciones. 
La representación femenina en el arte tiene distintos enfoques, sin embargo, es la visión occidental la cual ha predominado. De tal manera, el presente trabajo se enfoca en la imagen de la mujer de acuerdo con distintos teóricos y obras de arte para encaminarnos hacia el feminismo y la concepción de la mujer del siglo XXI, particularmente en México y Latinoamérica. Bajo la premisa de que los antecedentes artísticos nos sirven como pauta para la creación e influencian a los espectadores, se busca precisar los posibles orígenes del "deber ser" femenino. Por lo cual, se asume que las representaciones contienen prototipos y estos posteriormente colaboran a la idealización. En la actualidad, la expectativa acerca de un estilo de vida, una apariencia física y un comportamiento ideal se vuelve elitista e imposible de conseguir si no cuentas con las características económicas y fisonómicas. Uno de los propósitos del presente texto consiste en explicar cómo los paradigmas femeninos discriminan, precisamente por solo contemplar una de muchas visiones, sin valorar atributos desde su origen. Según Despentes (2015):

(...) el ideal de la mujer blanca, atractiva pero no puta, bien casada pero no relegada, que trabaja pero sin ser muy exitosa, para no humillar a su hombre, flaca pero no neurótica con la comida, que sigue indefinidamente joven sin que la desfiguren los cirujanos estéticos, que se siente plena con ser mamá pero no es acaparada por los pañales y los deberes de la escuela, buena ama de casa pero no sirvienta tradicional, culta pero menos que un hombre, esta mujer blanca feliz que nos ponen siempre frente a los ojos, que deberíamos esmerarnos para parecernos a ella, más allá de que parece aburrirse mucho por poca cosa, de todas formas nunca me la crucé, en ningún lugar. Creo que no existe (p. 3).

Con lo anterior, señala la aporía de las expectativas hacia la mujer. Por un lado, los roles representados en la pintura no surgen de manera espontánea, sino que la madre, la esposa, la hija, la virgen, la prostituta, la loca, la vagabunda, la reina y la campesina forman parte de las creencias populares e imitaciones de la realidad. Estas representaciones femeninas tienen cargas morales, jerárquicas y colaboran a reforzar lo entendido por estas ideas. Asimismo, Bourdieu (1998) menciona:

Como si la feminidad se resumiera en el arte de «empequeñecerse» (la feminidad, en bereber, se caracteriza por la forma del diminutivo), las mujeres permanecen encerradas en una especie de cercado invisible (del que el velo sólo es la manifestación visible) que limita el territorio dejado a los movimientos y a los desplazamientos de su cuerpo (mientras que los hombres ocupan más espacio con su cuerpo, sobre todo en los lugares públicos). (p. 43).

Así como Despentes exalta lo absurdo, Bourdieu indica la corta catalogación del género femenino y la relaciona a la limitación corporal. La manipulación del cuerpo se da a través de leyes y códigos morales, los cuales también dan preferencia a los hombres para dominar al Estado, relegan a la mujer por medio de ideas de maternidad y fragilidad, que también se ven reflejados en la falta de participación del género femenino en cuestiones políticas durante la historia. Lo anterior no indica la falta de interés o potencial de la mujer, sino la escasa oportunidad para su participación, es decir, se le relega a las labores domésticas y familiares. En la segunda década del siglo XXI, en México, hay aún debates y marchas a favor de la despenalización del aborto y las decisiones que tiene la mujer sobre su cuerpo (Domínguez, Becerril, Blancas, 2019, párr. 1).

Si la idea de que la definición social del cuerpo, y muy especialmente de los órganos sexuales, es el producto de un trabajo social de construcción ha pasado a ser completamente trivial, ya que ha sido defendida por toda la tradición antropológica, el mecanismo de la inversión de la relación entre las causas y los efectos que intento demostrar aquí, y gracias a la cual se ha operado la naturalización de esta construcción social, creo que no ha sido completamente descrito (Bourdieu, 1998, p. 36).

De acuerdo con lo anterior, se entiende cómo, al controlar el cuerpo de la mujer, se la reprime. Por lo tanto es importante señalar que los roles femeninos plasmados en el arte, a pesar de tener una carga histórica invaluable, no es excluyente que muestren el control del hombre sobre la mujer, limiten las perspectivas de sus roles y refuercen los estereotipos. Es decir, tanto la mujer como el hombre, tienen distintos matices de comportamiento, creencias y características físicas. Así pues, a principios de siglo XXI resulta impreciso catalogar a los géneros por medio de representaciones influenciadas por la moral y las creencias de otra época.

Por otro lado, el arte por su capacidad de reflejar su entorno, se proyectó en su momento con la intención de protestar o de vanagloriar la imposición de civilizaciones sobre otras. Por ejemplo, el Guernica en tono de protesta, o La libertad guiando al pueblo de Delacroix, en donde se engrandece la batalla. Por lo cual, cuando el arte occidental se da a conocer en otros territorios se vuelve la muestra del progreso intelectual de los europeos, por tanto, se 
convierte en la principal influencia y en prototipo de arte en países menos civilizados. Según Canclini (2001) “el creador más original siempre comienza siendo sujeto en el sentido de estar sujeto a una estructura" (p. 139). Con lo anterior, se busca identificar cómo el contexto del creador condiciona la obra. Es decir, el artista no impone sus parámetros estéticos, sino que refleja los de su sociedad, incluso cuando hace una crítica de ellos. De tal manera, las tendencias del arte occidental, los parámetros de creación, belleza y moral se impusieron y sirvieron de ejemplo para el creador latinoamericano. No obstante, Comisarenco (2010) señala que sí hay aspectos universales en el arte, lo cual pudiera encontrarse constantemente en las obras independientemente de su origen geográfico.

(...) la imagen primordial para el ser humano es la de la "Gran Madre", pues todos los seres humanos, más allá de nuestros respectivos géneros, somos hijos de una madre, que ineludiblemente constituye nuestra primera experiencia en el mundo. El arquetipo materno es consiguientemente una imagen interna propia de la mente humana que debido a su universalidad e importancia básica se encuentra presente en innumerables ritos, mitos, símbolos religiosos, sueños, fantasías, y obras artísticas de distinta índole desde la prehistoria hasta la época contemporánea (p. 193).

Ciertamente, los paradigmas femeninos plasmados en el arte, si bien son bellos, los creadores cuentan con el dominio de la técnica artística para representar con armonía. Asimismo, ejemplifican la pasión por el arte y la cultura, diferencian los atributos femeninos de los masculinos. De acuerdo con Giunta (2018) "La historia de las imágenes que abordan el cuerpo femenino es una de las más extensas en la historia del arte” (párr. 2). Las representaciones más reconocidas del arte forman parte de un pensamiento propio de su época y región, pero arcaicas en el siglo XXI. Es decir, no todo lo que se nos muestra en el arte clásico representa propiamente las diferentes versiones de la feminidad de su época, por consiguiente, tampoco las de la actualidad. Hoy en día replicar las figuras y pensamientos artísticos sería anacrónico. Por otro lado, para retomar la figura de la mujer, tampoco hay a lo largo de la historia del arte un reconocimiento a la creadora. Por ejemplo, fue hasta el siglo XXI cuando, de acuerdo con Smith (2018), Hilma at Klint (Véase figura 1) fue reconocida como la primera persona en utilizar el arte abstracto (párr. 4). Según Giunta (2018) "La mujer como creadora y tema del arte, en la que, paradójicamente, gran parte de las pinturas habían sido realizadas por hombres". Lo anterior, nos da una pista sobre quienes establecieron los conceptos de belleza o del “deber ser" en las representaciones femeninas pictóricas. Asimismo, según Danto (2005):

Picasso embelleció a las mujeres porque le gustaba la idea de una mujer hermosa obligada a sufrir. Una mujer fea, o una mujer afeada por la dureza de sus circunstancias, impide la posibilidad de este perverso placer. Pensemos, al fin y al cabo, en la historia de las representaciones de víctimas femeninas, desnudas y encadenadas a rocas, esperando a sus rescatadores. Me imagino que a nadie le despertaría interés erótico rescatar a una bruja, o a una mujer consumida y hambrienta. Pero esto significa que, en general, la belleza en la representación de las víctimas de este tipo está sujeta a una crítica moral relacionada no tanto con «la mirada» como con el hecho de que quien mira se complazca en el tormento de una mujer hermosa (p. 186).

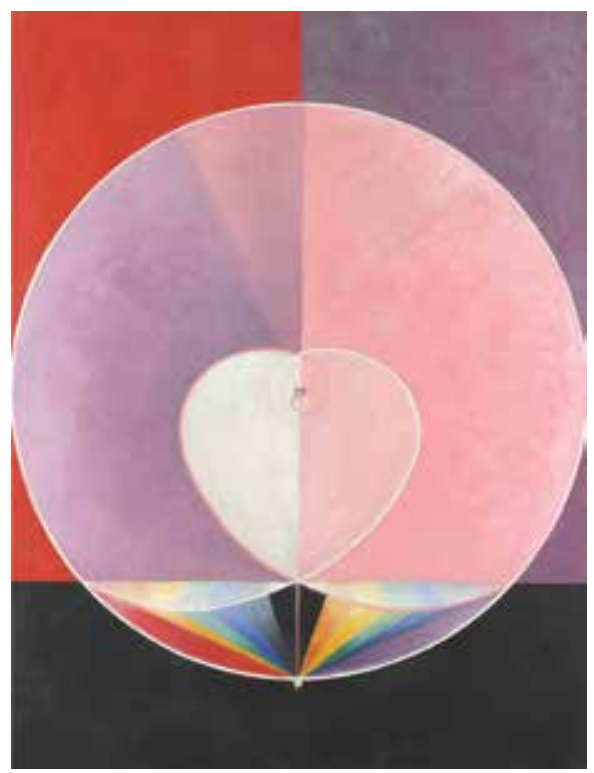

Figura 1. Hilma at Klint, Dove No. 2, 1915, Olomouc Museum of Art. Fuente: https://g. co/arts/rdNhrGeSJB1aGNgNA

De tal manera, Danto ejemplifica la necesidad del creador, en este caso el de Picasso, en representar la belleza de la mujer como un recurso para obtener la atención del espectador. Por lo cual, Picasso, al utilizar esta estrategia, ejerce su poder sobre la obra, pero también delimita lo que cree bello. Otros ejemplos los da Berger (2000), quien compara las imágenes publicitarias con pinturas, "Las poses adoptadas para denotar estereotipos de mujer: madre serena (madonna), secretaria que vive su vida (actriz, amante de rey), anfitriona perfecta (esposa 
del espectador-propietario), objeto sexual (Venus, ninfa sorprendida), etc" (p. 77). En efecto, hay un sistema simbólico arraigado sobre el cuerpo femenino. De acuerdo con lo anterior, Judith Butler (2007) menciona que "Los campos de «representación» lingüística y política definieron con anterioridad el criterio mediante el cual se originan los sujetos mismos, y Ia consecuencia es que Ia representación se extiende únicamente a lo que puede reconocerse como un sujeto" (p.46). Asimismo, según Despentes (2015):

El cuerpo colectivo funciona como un cuerpo individual: si el sistema es neurótico, engendra espontáneamente estructuras autodestructivas. Cuando el inconsciente colectivo, a través de esas herramientas de poder que son los medios y la industria del entretenimiento, sobrevalora la maternidad no es por amor a lo femenino, ni por benevolencia global. La madre investida de todas las virtudes, implica que se prepara al cuerpo colectivo para una regresión fascista. El poder otorgado por un Estado enfermo es necesariamente sospechoso (p. 12).

De acuerdo con lo anterior se deduce cómo los paradigmas representados en las imágenes son entonces una forma de difundir no solo conocimiento, sino el comportamiento colectivo. Otro ejemplo de distinción visual entre culturas o países son los rasgos físicos y deberes sociales de la mujer. Asimismo, Berger (2000) menciona las diferentes representaciones de la mujer desnuda en "el arte hindú, el arte persa, el arte africano, el arte precolombino" (p.30), las cuales tienen una intención, si bien para seducir, pero con una participación equitativa con el hombre, en contraste con el propósito de las pinturas europeas en las que la mujer representaba un "signo de sumisión" (p. 29).

Hay una clase de pintura europea al óleo cuyo tema principal y siempre recurrente son las mujeres. Esta clase es el desnudo. En los desnudos europeos encontramos algunos de los criterios y convenciones que han llevado a ver y juzgar a las mujeres como visiones (Berger, 2000, p. 27).

Con lo anterior, se busca hacer notar cómo en Europa hay cánones estéticos distintos a otros continentes. De tal modo, Berger nos permite continuar con esta idea sobre la concepción femenina idealizada desde su origen, es decir, desde el mundo occidental. Del mismo modo, cuando una civilización se impone sobre otra, más allá de las guerras y las conquistas, sino por medio de economías estables, se crea un dominio sobre los más vulnerables.
Más allá de la distancia étnica, religiosa, cultural o geográfica que pueda separar a las mujeres, la iconografía de la vulva, (...) se convierte en fuente de placer y en el núcleo central de la identidad femenina (...) las diferentes idealizaciones masculinas de la mujer a una reivindicación directa de su corporalidad, de su materialidad. (Escudero, 2003, p. 294)

Por otro lado, con relación con los usos y costumbres, en Latinoamérica solo tenían ritos y creencias propias de su región. Fue hasta la colonización cuando llegaron otros dogmas. En cuanto a la educación artística "La labor desarrollada por las academias en Iberoamérica estuvo centrada en la consolidación del estilo neoclásico que, en mayor o menor medida, perduró hasta el comienzo del siglo XX” (Espinosa, 2001, p. 109).

Ahora bien, si es cierto que la difusión a su producción cultural por las países imperialistas fue altamente beneficiosa para el desarrollo de las arte en el resto del mundo, no es menos cierto que esta acción benéfica se vio contrarrestada cuando convirtieron la cultura en un arma más de vasallaje y opresión colonial. En efecto, junto con sus manufacturas exportaran su literatura y su arte, pero no para enriquecer las culturas nacionales ya que existentes en las regiones colonizadas, sino para destruirlas o neutralizarlas, constatando en esto la obsecuencia de las oligarquías nativas (Carpani, 1961, p. 15).

Lo anteriormente mencionado contribuye a ejemplificar las diferentes concepciones sobre el arte, belleza, mujer y retrato, según su origen y tiempo. Los paradigmas femeninos representados en la pintura corresponden a un contexto, pero no todas las mujeres de otras regiones cumplen con las mismas características, tanto físicas como de los roles que juegan en la sociedad. Incluso, los paradigmas representados en un retrato femenino hecho en México durante el siglo XX se pueden volver obsoletos a través del tiempo. A pesar de lo anterior, la imagen de belleza de la mujer caucásica sigue predominando en la publicidad y en el arte sobre otro tipo de mujeres. Por esta razón, se hace notorio en México $^{1}$ el conflicto sobre la apertura de conceptos como la belleza o los roles femeninos. Según Bourdieu (1998):

La actitud sumisa que se impone a las mujeres cabileńas es el límite de la que, en la actualidad, sigue imponiéndose a las mujeres en Estados Unidos o en Europa, y que, como han demostrado muchos observadores, se basa en unos cuantos imperativos:

1 En otros países del primer mundo se puede ver la iniciativa de inclusión de bellezas en campañas publicitarias, certámenes, etcétera. 
sonreír, bajar la mirada, aceptar las interrupciones (p.

43).

$\mathrm{El}$ arte es un concepto abierto que se sujeta a nuevas visiones e interpretaciones, en el se "crean, a su modo, mundos artificiales e ilusorios" (Escudero, 2003, p. 305) por medio de movimientos artísticos. Así pues, es en el mundo contemporáneo donde la globalización y el mercado marcan las tendencias del arte y dan cabida a integrar a las producciones antes relegadas, también surge la integración de movimientos artísticos con una postura crítica hacia el arte pasado y la presente sociedad conservadora.

Las mujeres habían querido - $-\mathrm{y}$, como demuestra la literatura, aún siguen queriendo- definir la belleza femenina como se supone que los hombres la definen y convertirse en aquello que los hombres quieren que ellas sean. Contemporáneas del afro fueron las quemas rituales de sujetadores, en las que una prenda identificada con la feminidad y que servía para construir una figura femenina con arreglo a ciertas líneas era proscrita y a cambio se ensalzaban los contornos naturales de la mujer. Los pechos quedaban en libertad, los pezones se marcaban a través de las camisetas. Y, contemporánea al surgimiento de una cultura negra politizada, apareció una cultura femenina politizada con la que las mujeres buscaron vivir de acuerdo con su propia realidad sexual tal y como ellas la entendían, una cultura en la que la belleza como se había postulado anteriormente era ahora vista como una trampa.

Por último, aunque la mujer mexicana y latinoamericana no pertenece a una minoría dentro de su propio contexto, el género femenino sí resulta ser parte de un sector vulnerable y con imposiciones eurocéntricas. Se entiende entonces cómo cada mujer cuenta con una diversidad de características, algunas de ellas la vuelven aún más susceptible, como la pobreza, la falta de educación, la etnia, etcétera. De tal manera, es conveniente especificar las propiedades del arte, tanto los atributos como imposiciones ideológicas. Si bien, las obras con representaciones con figuras femeninas son enriquecedoras, a su vez han servido para distorsionar la percepción. Es decir, las identidades y roles en Latinoamérica, no concuerdan con los parámetros femeninos plasmados en el arte occidental. Latinoamérica tiene sus propias economías, espacios geográficos y creencias específicas, alejadas de las imágenes renacentistas o de cualquier otro movimiento artístico hecho en otro tiempo y espacio. Finalmente, la creencia de que las obras buscan representar contenido universal por medio de las emociones sigue vigente, no obstante, es necesario superar ideas preconcebidas.

\section{Referencias}

Berger, J. (2000). Modos de ver. Barcelona: Gustavo Gili.

Bourdieu, P. (1998). La dominación masculina. París: Editorial Anagrama.

Butler, J. (2007). El género en disputa: el feminismo y la subversión de la identidad. Nueva York: Ediciones Paidos Ibérica, S.A.

Carpani, R. (1961). Arte y revolución en América Latina. Buenos Aires, Argentina: Editorial Coyoacán.

Comisarenco, D. (2010). Diosas y madres, el arquetipo femenino en Diego Rivera. Athenea Digital, 19 (noviembre), 191-212.

Danto, A. (2005). El abuso de la belleza: la estética y el concepto del arte. Barcelona, España: Paidós Ibérica.

Despentes, V. (2015). Teoría King Kong. Lectulandia, 76.

Escudero, J. A. (2003). Estéticas feministas contemporáneas (o de cómo hacer cosas con el cuerpo). Anales de Historia del Arte, 13, 287-305.

Espinosa, G. (2001). El retrato femenino en México durante el siglo XIX. Tiempos de América, 8(8), 107-120.

Natalia Encinas, G. M. (2018). “Aquelarre subversiva”. Políticas de autorrepresentación en las prácticas artísticas feministas populares y migrantes, Cooperativa Gráfica La Voz de la Mujer. Discurso Visual, 42, 26-36.

García Canclini, N. (2001). La producción simbólica: teoría y método en sociología del arte. D.F., México: Siglo Veintiuno Editores.

Domínguez, P. Becerril, J. (2019). Día Internacional de la Mujer: marcha minuto a minuto. Recuperado de https:// www.milenio.com/politica/comunidad/por-dia-de-lamujer-marchan-sobre-reforma-minuto-a-minuto

Smith, R. (2018). 'Hilma Who?' No More - The New York Times. Recuperado de https://www.nytimes. com/2018/10/11/arts/design/hilma-af-klintreview-guggenheim.html 